\title{
Surface-active and Photochemical Properties of Sodium p-Dodecylbenzylsulfate in Aqueous Solution
}

\author{
Yoshihiro Itoh, Kenji Yamamoto, and Satoshi Horiuchi
}

Division of Chemistry and Materials, Faculty of Textile Science and Technology, Shinshu University, Nagano, Japan

Address correspondence to Yoshihiro Itoh, Functional Polymer Science Course, Division of Chemistry and Materials, Faculty of Textile Science and Technology, Shinshu University, Ueda, Nagano 386-8567, Japan

E-mail: yositoh@shinshu-u.ac.jp

\begin{abstract}
A UV-degradative anionic surfactant, sodium p-dodecylbenzylsulfate, was prepared and its surface-active and photochemical properties in water were examined. The surface activities such as solubilizing, foaming, and dispersing powers were as good as those of synthetic detergents, linear alkylbenzenesulfonate and sodium dodecylsulfate. Upon UV irradiation, the surfactant was degraded to give $p$-dodecylbenzyl alcohol, a nonsurfactant.
\end{abstract}

Keywords Photodegaradation, anionic surfactant, nonsurfactant, benzylsulfate

Shortened Title Properties of Dodecylbenzylsulfate 


\section{INTRODUCTION}

Environmental concerns have been paid to the development of biologically and chemically cleavable surfactants. ${ }^{[1,2]}$ Among them, UV-cleavable surfactants are attractive because UV irradiation after their use would convert them to non-surfactants without any other additives such as acid and base. ${ }^{[3,4]}$ These surfactants may serve as photofunctional materials as well as environmentally benign detergents. ${ }^{[5]}$

We have reported that a cationic surfactant, p-dodecylbenzyltrimethylammonium bromide $\left(\mathrm{C}_{12} \mathrm{BA}\right)$ is easily degraded by UV irradiation to yield a nonsurfactant. ${ }^{[6]}$ This surfactant has been also used as a photocleavable emulsifier for microemulsion polymerization which gives surfactant-free polymers. ${ }^{[7]}$ We also emphasize that this type of surfactants are stable under usual conditions (e.g., stable to solar irradiation and non-hydrolysable in acidic and basic solutions) and are surface-active as good as commercially available cationic surfactants. ${ }^{[6,8]}$

Here we report the surface-active and photochemical properties of a novel anionic surfactant, sodium $p$-dodecylbenzylsulfate $\left(\mathrm{C}_{12} \mathrm{BS}\right)$, which is expected to be an alternative to one of the most commercially available and the most important synthetic detergents, linear alkylbenzenesulfonate (LAS).

\section{EXPERIMENTAL}

\section{Materials}

Sodium dodecylbenzenesulfonate (LAS: soft type) and sodium dodecylsulfate (SDS: reagent for ion-pair chromatography) were purchased from Tokyo Kasei (Japan) and used without any further purification.

Sodium p-dodecylbenzylsulfates were prepared from $n$-dodecylbenzene (Tokyo Kasei: guaranteed reagent) or dodecylbenzene (Tokyo Kasei: extra pure; soft type; mixture of linear 
chain isomers) as outlined in Scheme 1.

p-Dodecylbenzylbromide ${ }^{[9]} \quad$ To a mixture of dodecylbenzene (20 g, $0.081 \mathrm{~mol}$ ), paraformaldehyde (4.3 g, $0.14 \mathrm{~mol}$ ), sodium bromide (25.2 g, $0.24 \mathrm{~mol}$ ), and acetic acid (5 $\mathrm{ml})$ was added dropwise a mixture of acetic acid $(16 \mathrm{ml})$ and sulfuric acid $(16 \mathrm{ml})$, and then stirred for $7 \mathrm{~h}$ at $70{ }^{\circ} \mathrm{C}$. The reaction mixture was poured into ice-cold water and extracted with ethyl ether, dried over anhydrous $\mathrm{MgSO}_{4}$ and then evaporated. The crude product was purified by silica-gel column chromatography with $n$-hexane as an eluent to give colorless oil: yield of the product prepared from dodecylbenzene, $54 \%$; ${ }^{1} \mathrm{H}$ NMR $\left(\mathrm{CDCl}_{3}\right) \delta$ (ppm): 0.88 (t, J=6.6 Hz, 3H, $\mathrm{CH}_{3}$ ), 1.26 (broad s, 18H, Ar-C-C-( $\left.\left(\mathrm{CH}_{2}\right)_{9}\right)^{-}$), 1.59 (broad s, 2H, Ar-C-CH $-\mathrm{C}-$ ), 2.58 (t, J=8.1 Hz, 2H, Ar- $\mathrm{CH}_{2}-\mathrm{C}-$ ), 4.48 (s, 2H, $\mathrm{Ar}-\mathrm{CH}_{2}-\mathrm{Br}$ ), 7.20-7.38 (m, 4H, Ar).

p-Dodecylbenzyl alcohol ${ }^{[10]} \quad$ A mixture of p-dodecylbenzylbromide (15 g, 0.044 mol), sodium acetate (82.1 g, $1.0 \mathrm{~mol}$ ), and $250 \mathrm{ml}$ of acetic acid was refluxed for $7 \mathrm{~h}$. Water was added to the solution and then extracted with ethyl ether. The extract was dried over $\mathrm{MgSO}_{4}$ and then evaporated. The crude product was purified by silica-gel column chromatography with $n$-hexane as an eluent to give $p$-dodecylbenzyl acetate as colorless oil: yield of the product from dodecylbenzene, $68 \%$. To the acetate $(9.5 \mathrm{~g}, 0.030 \mathrm{~mol})$ in a mixture of tetrahydrofuran $(50 \mathrm{ml})$ and methanol $(50 \mathrm{ml})$ was added $10 \%$ of aqueous $\mathrm{KOH}$ (5 $\mathrm{ml})$ and then stirred for $30 \mathrm{~min}$ at room temperature. The solution was treated as described above to give $p$-dodecylbenzyl alcohol as colorless oil: yield of the product from dodecylbenzene, $74 \% ;{ }^{1} \mathrm{H}$ NMR $\left(\mathrm{CDCl}_{3}\right) \delta(\mathrm{ppm})=0.7-2.7$ (m, 25.2H, alkyl), 4.65 (s, 2H, Ar- $\left.\mathrm{CH}_{2}-\mathrm{O}\right)$, 7.1-7.3 (m, 4H, Ar).

Sodium p-dodecylbenzylsulfate ${ }^{[11]}$ To a mixture of sulfur trioxide-pyridine complex (4.2 g, $0.027 \mathrm{~mol})$ and pyridine $(20 \mathrm{ml})$ was added dropwise a solution of $p$-dodecylbenzyl alcohol (4.1 g, $0.015 \mathrm{~mol})$ in pyridine $(10 \mathrm{ml})$, and stirred for $3 \mathrm{~h}$ at room temperature. The solution was then neutralized with aqueous $\mathrm{NaOH}$. The water-insoluble product $\left(n-\mathrm{C}_{12} \mathrm{BS}\right.$ : prepared from $n$-dodecylbenzene) was recrystallized from methanol and the water-soluble one ( $\mathrm{C}_{12} \mathrm{BS}$ : from dodecylbenzene) was purified by extraction with methanol. 
n-C ${ }_{12} \mathrm{BS}$ : white powder; yield, $35 \%$; mp 161-164 ${ }^{\circ} \mathrm{C} ;{ }^{1} \mathrm{H}$ NMR (DMSO-d $\left.{ }_{6}\right) \delta$ (ppm): 0.85 (t, J=6.6 Hz, 3H, CH CH $_{3} 1.23$ (broad s, 18H, Ar-C-C- $\left.\left(\mathrm{CH}_{2}\right)_{9}-\right)$ ), 1.54 (broad s, 2H, Ar-C- $\mathrm{CH}_{2}-$ ), 2.50-2.57 (m, 2H, Ar-CH$-\mathrm{C}-$ ), 4.73 (s, 2H, $\left.\mathrm{Ar}-\mathrm{CH}_{2}-\mathrm{O}\right), 7.12-7.23$ (m, 4H, Ar).

$\mathrm{C}_{12} \mathrm{BS}$ : waxy solid; yield, $74 \%$; ${ }^{1} \mathrm{H}$ NMR $\left(\mathrm{CDCl}_{3}\right) \delta$ (ppm): 0.55-0.90 (m, 6.2H, $\mathrm{CH}_{3}$ ), 0.92-1.56 (m, 17.5H, Ar-C-( $\left.\left(\mathrm{CH}_{2}\right)_{9}-\right)$, 2.15-2.52 (m, 1H, Ar-CH(C)-C-), 4.98 (broad s, 2H, Ar- $\left.\mathrm{CH}_{2}-\mathrm{O}\right), 6.80-7.20$ (m, 4H, Ar).

Sodium p-methylbenzylsulfate $\left(C_{1} B S\right)^{[11]} \quad C_{1} B S$ was prepared from $p$-methylbenzyl alcohol in a similar way as described above and recrystallized from acetone; white powder; yield, $28 \%$; ${ }^{1} \mathrm{H}-\mathrm{NMR}\left(\mathrm{D}_{2} \mathrm{O}\right) \delta$ (ppm): 2.32 (s, 3H, $\left.\mathrm{Ar}-\mathrm{CH}_{3}\right), 4.99$ (s, 2H, Ar- $\left.\mathrm{CH}_{2}-\mathrm{O}\right), 7.2,7.3$ (dd, J=7.8 Hz, 4H, Ar).

\section{Measurements}

NMR spectra were recorded on a Bruker AVANCE400 spectrometer at room temperature. GC/MS spectra were obtained on a JEOL JMS-K9 mass spectrometer. HPLC was performed on a Jasco liquid chromatography system, as reported previously. ${ }^{[8]}$

Krafft temperature was determined as the temperature above which a $1 \mathrm{wt} \%$ of surfactant was soluble in water. Critical micelle concentration (CMC) was determined fluorometrically by observing the vibrational peak ratio $\left(\mathrm{I}_{3} / \mathrm{I}_{1}\right)$ of pyrene fluorescence. ${ }^{[8,12]}$ Solubilizing power was estimated from the concentration of Oil Orange SS (1-(o-tolylazo)-2-naphthol) solubilized in $0.25 \mathrm{wt} \%$ of surfactant solution after standing for 3 $\mathrm{h}$ at $25{ }^{\circ} \mathrm{C} .{ }^{[13]}$ Foaming power was defined as the foaming volume of a $0.023 \mathrm{wt} \%$ of surfactant solution $(7 \mathrm{ml})$ in a $50 \mathrm{ml}$ graduated vial after vigorously shaking followed by standing for $3 \mathrm{~min}$ at $25{ }^{\circ} \mathrm{C}$. Dispersing power was estimated from the transmittance at 500 $\mathrm{nm}$ for the supernatant fraction of $0.25 \mathrm{wt} \%$ of surfactant solution $(50 \mathrm{ml})$ in which carbon black (70 mg) was dispersed followed by standing for $3 \mathrm{~h}$ at $25{ }^{\circ} \mathrm{C}$ : a lower value indicates a higher dispersing power.

For quantitative photolyses, irradiations were carried out with a $30-\mathrm{W}$ low-pressure mercury lamp (EIKOHSHA, EL-J-60; the main light emission is a 254-nm line) in a 
merry-go-round apparatus. ${ }^{[8]}$ A $10 \mathrm{mM}$ of aqueous solution $(4 \mathrm{ml})$ was placed in a quartz tube $(13 \mathrm{~mm} \phi)$ and irradiated for $10 \mathrm{~min}$ at $25{ }^{\circ} \mathrm{C}$ under argon, air, or oxygen atmosphere. The conversion yield of $\mathrm{C}_{1} \mathrm{BS}$ was determined by HPLC. The identification and quantification of its benzylic products were also performed by HPLC. The conversion yield of $\mathrm{C}_{12} \mathrm{BS}$ and the yield of its benzylic products were determined by ${ }^{1} \mathrm{H}$ NMR.

\section{RESULTS AND DISCUSSION}

\section{Preparation}

Sodium $p$-dodecylbenzylsulfate $\left(n-\mathrm{C}_{12} \mathrm{BS}\right)$ prepared from $n$-dodecylbenzene was insoluble in water at room temperature (Krafft temperature, $59{ }^{\circ} \mathrm{C}$ ). Then a water-soluble type of it was prepared in the same way using a lower grade of dodecylbenzene as the starting material. The latter compound $\left(\mathrm{C}_{12} \mathrm{BS}\right.$ : Krafft temperature, $\left.<0{ }^{\circ} \mathrm{C}\right)$ will be used hereafter. The ${ }^{1} \mathrm{H}$ NMR, ${ }^{13} \mathrm{C}$ NMR, and GC/MS spectra of dodecylbenzene and $\mathrm{C}_{12} \mathrm{BS}$ demonstrated that these compounds are mixtures of different alkyl chain homologues $\left(\mathrm{C}_{10}-\mathrm{C}_{13}\right)$ with a phenyl group attached at 2-, 3-, 4-, 5-, and 6-positions on the alkyl chain: ${ }^{[14,15]}$ see supplementary material.

\section{Surface-active Properties}

In Table 1, several surface-active properties of $\mathrm{C}_{12} \mathrm{BS}$ are compared with commercial products, LAS and SDS. The values of CMC, solubilizing power, and foaming power for $\mathrm{C}_{12} \mathrm{BS}$ are comparable to those for LAS. Interestingly, $\mathrm{C}_{12} \mathrm{BS}$ is superior to LAS and SDS in dispersing carbon black. These excellent surface-active properties of $\mathrm{C}_{12} \mathrm{BS}$ may be partially due to the presence of a hydrophobic benzyl moiety. It should be also noted that $\mathrm{C}_{12} \mathrm{BS}$ is stable under usual conditions and not appreciably hydrolyzed in dilute acidic and basic solutions $(12>\mathrm{pH}>2)$ below $40{ }^{\circ} \mathrm{C}$. 


\section{Photolysis}

In order to estimate the photolysis mechanism of this type of compounds, the products for $\mathrm{C}_{1} \mathrm{BS}$ and $\mathrm{C}_{12} \mathrm{BS}$ were identified by HPLC and NMR, respectively. Irradiation of the aqueous solutions gave $p$-methylbenzyl alcohol for $\mathrm{C}_{1} \mathrm{BS}$ and $p$-dodecylbenzyl alcohol for $\mathrm{C}_{12} \mathrm{BS}$ as a major benzylic product (Table 2): the yields were around $80 \%$ based on the substrate consumed. As minor products, $p$-alkyltoluene was obtained preferentially under deaerated condition and p-alkylbenzaldehyde was done under aerated one: the yields were less than a few \%. Although ionic products have not been specified yet, sulfate or hydrogensulfate anion seems to be finally formed. This may be supported by the fact that barium salts (sulfate or sulfite) were precipitated by addition of barium chloride to the supernatant of the irradiated solution: sulfite, if any, seems to be oxidized by oxygen to finally give sulfate. The above results and the fact that the photolysis in methanol gives the corresponding methyl ether as a main product strongly suggest that heterolytic cleavage of the benzyl-oxygen bond in $\mathrm{C}_{1} \mathrm{BS}$ and $\mathrm{C}_{12} \mathrm{BS}$ occurs predominantly (Scheme 2). These facts are in contrast to our previous result that the corresponding ammonium salts, p-alkylbenzyltrimethylammonium chlorides, undergo both homolytic and heterolytic cleavages to give certain amounts of $p$-alkyltoluene, $p$-alkylbenzaldehyde, and $p$-alkylbenzyl alcohol. $^{[6,8]}$ It should be noted that the conversion yield of $\mathrm{C}_{12} \mathrm{BS}$ is remarkably higher than that of $\mathrm{C}_{1} \mathrm{BS}$ (Table 2). However, we have no clear evidence for the higher photo-degradability of $\mathrm{C}_{12} \mathrm{BS}$.

Table 3 shows some solution properties of $\mathrm{C}_{12} \mathrm{BS}$ before and after irradiation. Upon irradiation for $20 \mathrm{~min}$ the solution $(10 \mathrm{mM})$ became turbid, and after almost complete photolysis (3-h irradiation) the transmittance of the solution at $500 \mathrm{~nm}$ decreased to $0 \%$ and its foaming disappeared. These clearly indicate the formation of water-insoluble products and thus the conversion to a nonsurfactant solution. Furthermore, the production of acidic ions (probably sulfate) increased the solution conductivity and decreased the $\mathrm{pH}$ value.

It is interesting to note that nonsurfactant products such as $p$-dodecylbenzyl alcohol can be extracted quantitatively with organic solvents. In addition, our preliminary experiment 
showed that $\mathrm{C}_{12} \mathrm{BS}$, as well as $\mathrm{C}_{12} \mathrm{BA},{ }^{[7]}$ can be used as a photocleavable emulsifier for microemulsion polymerization of methyl methacrylate in water, which gives surfactant-free polymers. These facts exemplify the usability of $\mathrm{C}_{12} \mathrm{BS}$ in separation and purification technologies.

\section{CONCLUSION}

It has been demonstrated that a novel UV-cleavable anionic surfactant, $\mathrm{C}_{12} \mathrm{BS}$, has surface activities comparable to or superior to those of LAS and SDS, which disappear completely on UV irradiation. Therefore, $\mathrm{C}_{12} \mathrm{BS}$ will be used not only as a cleavable alternative to LAS in widespread usage but also as a photo-functional surfactant.

\section{Acknowledgments}

This work was partially supported by a Grant-in-Aid for Scientific Research (No. 20550168) and a Grant-in-Aid for Global COE Program from the Ministry of Education, Culture, Sports, Science, and Technology of Japan. 


\section{REFERENCES}

[1] Benvegnu, T., Plusquellec, D., and Lemiegre, L. (2008) In Monomers, polymers, and composites from renewable resources, edited by M.N. Belgacem and A. Gandini; Oxford, Elsevier; pp. 152-178.

[2] Lundberg, D., Stjerndahl, M., and Holmberg, K. (2008) Adv. Polym. Sci., 218: 57-82.

[3] Nuyken, O., Meindl, K., Wokaun, A., and Mezger, T. (1994) J. Photochem. Photobiol. A: Chem., 81: 45-53.

[4] Dunkin, I.R., Gittinger, A., Sherrington, D.C., and Whittaker, P. (1996) J. Chem. Soc., Perkin Trans. 2, 1837-1842.

[5] Wang, B.Y., Xu, H., and Zhang, X. (2009) Adv. Mater., 21: 2849-2864.

[6] Itoh, Y., Yamamoto, K., and Shirai, H. (2003) Chem. Lett., 32: 8-9.

[7] Itoh, Y., Horiuchi, S., and Yamamoto, K. (2005) Chem. Lett., 34: 814-815.

[8] Itoh, Y., Horiuchi, S., and Yamamoto, K. (2005) Photochem. Photobiol. Sci., 4: 835-839.

[9] Kubiczek, G. and Neugebauer, L. (1950) Monatsh. Chem., 81: 917-920.

[10] Abramo, J.G. and Chapin, E.C. (1961) J. Org. Chem., 26: 2671-1673.

[11] Duff, R.B. (1949) J. Chem. Soc., 1597-1600.

[12] Kalyanasundaram, K. and Thomas, J.K. (1977) J. Am. Chem. Soc., 99: 2039-2044.

[13] Namba, Y., Hayashi, S., and Fuchizawa, T. (1955) Yukagaku, 4: 238-244.

[14] Wainai, T., Kanemoto, H., and Mashimo, K. (1983) Bunseki Kagaku, 32: T123-T128.

[15] Itoh, M., Shimokawa, S., Arase, A., and Aomura, K. (1965) Kogyo Kagaku Zasshi, 68: 1441-1445.

[16] Mukerjee, P. and Mysels, K.J. (1971) Nat. Stand. Ref. Data Ser., Nat. Bur. Stand., 36: 51-92. 
TABLE 1

Surface-active properties of surfactants in $\mathrm{H}_{2} \mathrm{O}$ at $25^{\circ} \mathrm{C}$

\begin{tabular}{lcccc}
\hline Surfactant & $\begin{array}{c}\text { CMC } \\
(\mathrm{mM})\end{array}$ & $\begin{array}{c}\text { Solubilizing } \\
\text { Power }\left(\mathrm{mg} \mathrm{l}^{-1}\right)\end{array}$ & $\begin{array}{c}\text { Foaming } \\
\text { Power }(\mathrm{ml})\end{array}$ & $\begin{array}{c}\text { Dispersing } \\
\text { Power (\%) }\end{array}$ \\
\hline $\mathrm{C}_{12} \mathrm{BS}$ & 1.0 & 11.3 & 29 & 0.1 \\
LAS & $1.2(2)^{a}$ & 10.5 & 38 & 17 \\
SDS & $8.2(8)^{a}$ & 2.7 & 5 & 33 \\
\hline
\end{tabular}

${ }^{a}$ Ref. 16.

TABLE 2

Conversion and product yields (\%) for photolyses of $\mathrm{C}_{1} \mathrm{BS}$ and $\mathrm{C}_{12} \mathrm{BS}$ in $\mathrm{H}_{2} \mathrm{O}$ at $25{ }^{\circ} \mathrm{C}^{a}$

\begin{tabular}{lccccc}
\hline Substrate & Atmosphere & Conversion & Alcohol & Alkyl & Aldehyde \\
\hline $\mathrm{C}_{1} \mathrm{BS}$ & Argon & 31 & 86 & 2 & $-0^{b}$ \\
& Air & 25 & 84 & $-0^{b}$ & $-0^{b}$ \\
& Oxygen & 27 & 79 & $-0^{b}$ & 3 \\
$\mathrm{C}_{12} \mathrm{BS}$ & Air & 62 & 81 & 1 & $-0^{b}$ \\
\hline
\end{tabular}

${ }^{a}$ [Substrate]=10 mM; irradiation time, 10 min; Alcohol, $p$-alkylbenzyl alcohol; Alkyl, p-alkyltoluene; Aldehyde, $p$-alkylbenzaldehyde.

${ }^{b}$ Less than $0.5 \%$. 
TABLE 3

Solution properties of $\mathrm{C}_{12} \mathrm{BS}$ before and after irradiation at $25{ }^{\circ} \mathrm{C}$

\begin{tabular}{|c|c|c|c|c|c|}
\hline Irradiation $^{a}$ & $\begin{array}{c}\text { Conversion }^{b} \\
(\%) \\
\end{array}$ & $\begin{array}{c}\text { Transmittance }^{c} \\
(\%) \\
\end{array}$ & $\begin{array}{c}\text { Foaming } \\
\text { Power }^{d}(\mathrm{ml})\end{array}$ & $\begin{array}{l}\text { Conductivity } \\
(\mathrm{mS} / \mathrm{cm})\end{array}$ & $\mathrm{pH}$ \\
\hline Before & 0 & 100 & 29 & 0.4 & 5.6 \\
\hline After & 92 & 0 & 0 & 3.1 & 2.6 \\
\hline
\end{tabular}

${ }^{a}\left[\mathrm{C}_{12} \mathrm{BS}\right]=10 \mathrm{mM}$; irradiation time, $3 \mathrm{~h}$.

${ }^{b}$ Conversion yield of $\mathrm{C}_{12} \mathrm{BS}$.

${ }^{c}$ Transmittance of the solution at $500 \mathrm{~nm}$.

${ }^{d}$ See Table 1. 


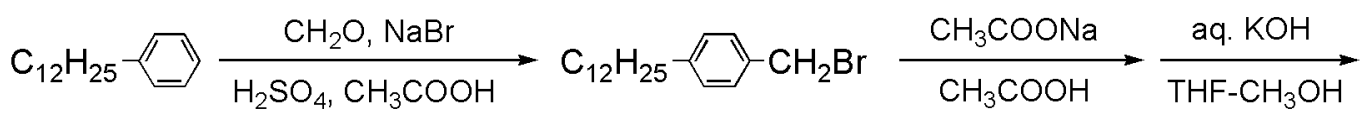

$$
\begin{aligned}
& \mathrm{C}_{12} \mathrm{H}_{25}-\mathrm{CH}_{2} \mathrm{OH} \underset{\text { Pyridine }}{\stackrel{\substack{\mathrm{SO}_{3} \text {-Pyridine } \\
\text { complex }}}{\longrightarrow} \stackrel{\text { aq. } \mathrm{NaOH}}{\longrightarrow}} \mathrm{C}_{12} \mathrm{H}_{25}-\mathrm{CH}_{2} \mathrm{OSO}_{3}{ }^{\ominus} \mathrm{Na}^{\oplus}
\end{aligned}
$$

SCH. 1. Synthesis of $\mathrm{C}_{12} \mathrm{BS}$

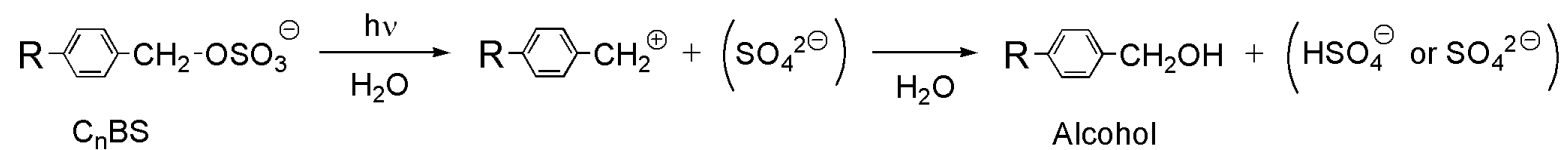

SCH. 2. Photolysis of $\mathrm{C}_{n} \mathrm{BS}$ 


\section{SUPPLEMENTARY MATERIAL}

\section{Chemical Structures of Dodecylbenzene and $\mathrm{C}_{12} \mathrm{BS}$}

To estimate the detailed chemical structure of $\mathrm{C}_{12} \mathrm{BS},{ }^{13} \mathrm{C}$ NMR, ${ }^{1} \mathrm{H}$ NMR, and GC/MS spectra of a starting materials used for the preparation of it, dodecylbenzene (DB: soft type, mixture of linear chain isomers) were obtained. Figures 1 and 2 show the ${ }^{13} \mathrm{C}$ NMR and ${ }^{1} \mathrm{H}$ NMR spectra, respectively. The signal peaks were assigned according to the reported data. ${ }^{[14,15]}$ Judging from the chemical shifts and peak intensities, DB is a mixture of structural isomers whose phenyl group is attached at 2- to 6-positions on the alkyl chain. Gas chromatograms of DB detected by GC/MS are shown in Figures 3. Figure 3(a) clearly indicates that $\mathrm{DB}$ is a mixture of different alkyl chain homologues $\left(\mathrm{C}_{10}\right.$ to $\left.\mathrm{C}_{13}\right)$. Figure 3 (b) confirms the presence of the foregoing isomers, each of which is composed of two species which have not been defined yet. Table 1 lists the fractions of the components calculated from the peak area in Figure 3(a).

On the other hand, $\mathrm{C}_{12} \mathrm{BS}$ exhibited more complicated ${ }^{13} \mathrm{C}$ NMR and ${ }^{1} \mathrm{H}$ NMR spectra because the present preparation method gave position isomers (ortho, meta, and para) for each of the foregoing compounds. Further examination thus remains to be solved. 


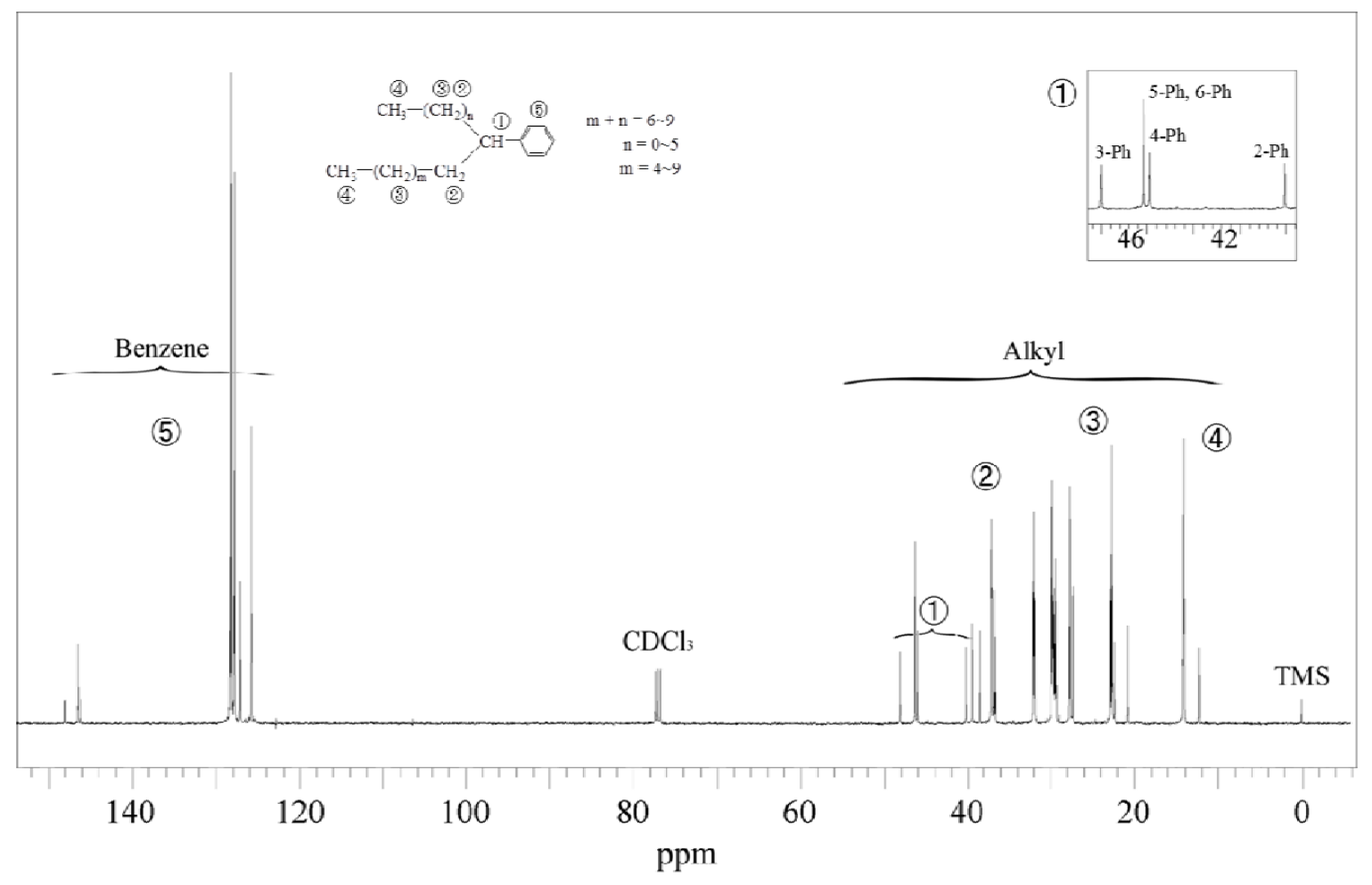

Figure $1{ }^{13} \mathrm{C}$ NMR spectrum of $\mathrm{DB}$ in $\mathrm{CDCl}_{3}$ : insert shows the magnified spectrum of peaks (1) for $\alpha$-methene carbons. 


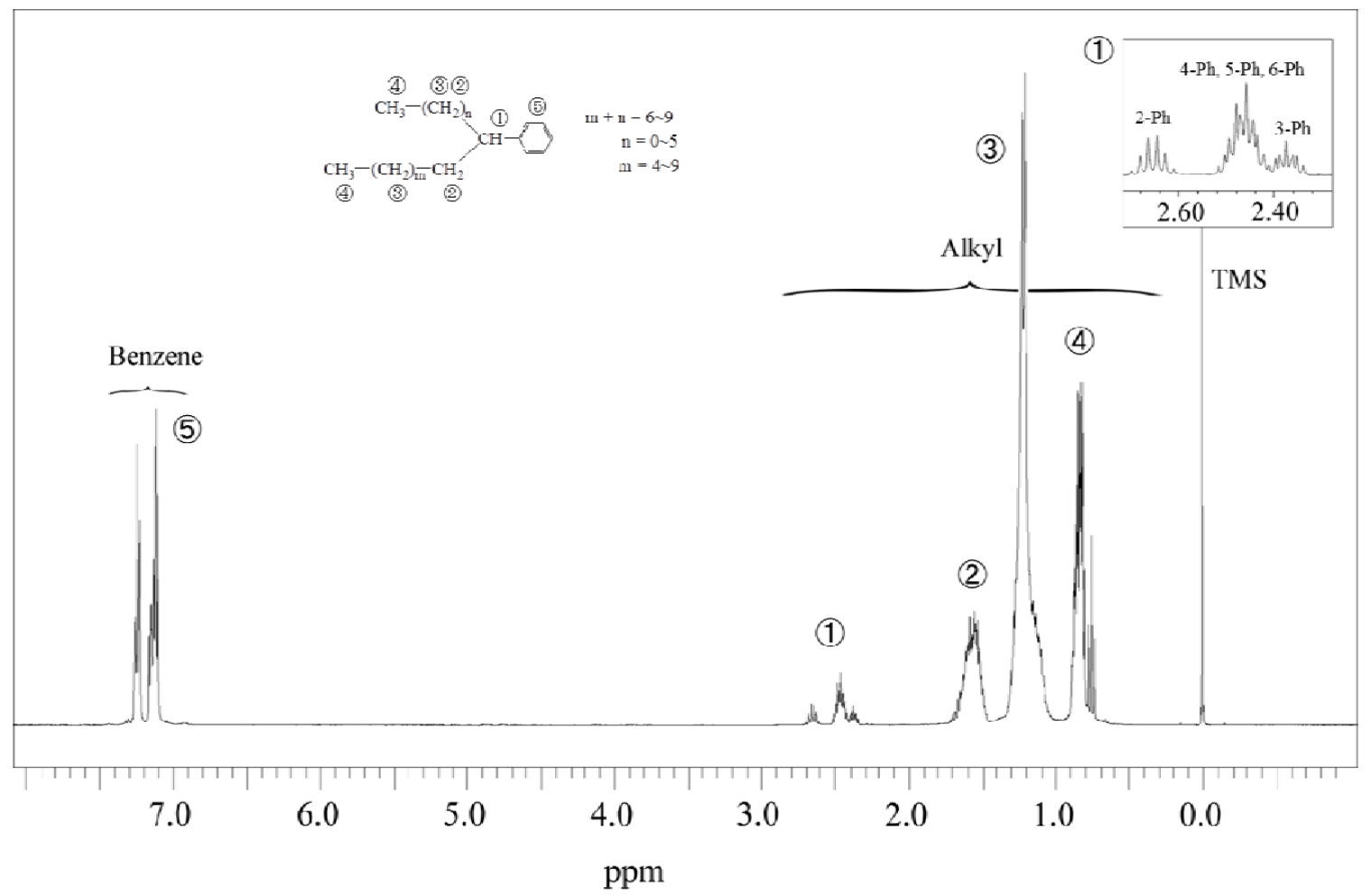

Figure $2{ }^{1} \mathrm{H}$ NMR spectrum of $\mathrm{DB}$ in $\mathrm{CDCl}_{3}$ : insert shows the magnified spectrum of peaks (1) for $\alpha$-methene protons. 

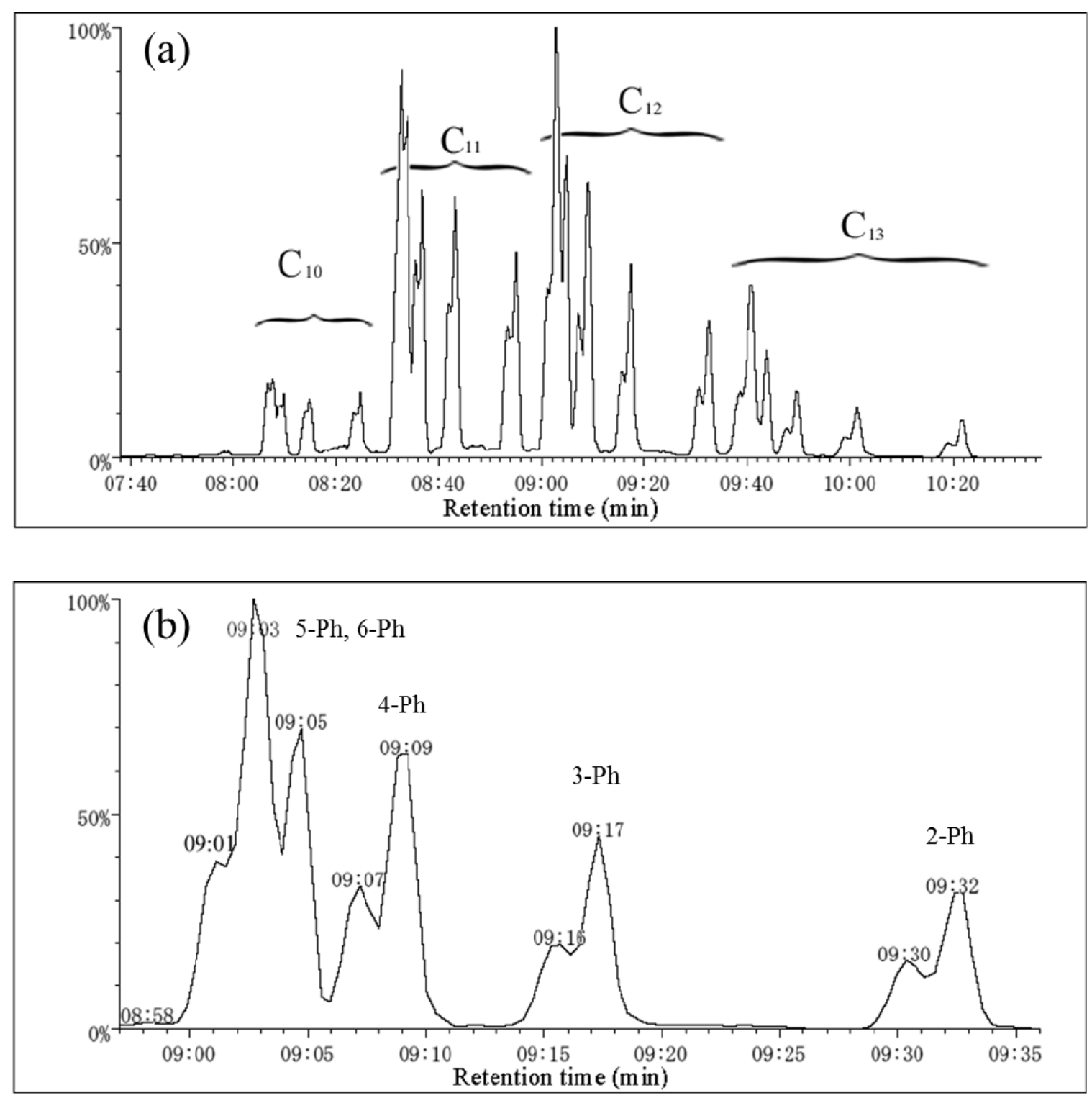

Figure 3 Gas chromatograms of DB detected by GC/MS: (a) total chromatogram; (b) magnified chromatogram for $\mathrm{C}_{12}$ portions. 
TABLE 1

Fractions (\%) of components of $\mathrm{DB}^{a}$

\begin{tabular}{cccccc}
$\mathrm{C}_{\mathrm{n}}{ }^{b}$ & 2-Phenyl & 3-Phenyl & 4-Phenyl & 5- \& 6-Phenyl & Total \\
\hline $\mathrm{C}_{10}$ & 2 & 2 & 2 & 3 & 8 \\
$\mathrm{C}_{11}$ & 7 & 8 & 8 & 16 & 40 \\
$\mathrm{C}_{12}$ & 5 & 6 & 8 & 18 & 37 \\
$\mathrm{C}_{13}$ & 2 & 2 & 2 & 9 & 15 \\
Total & 16 & 18 & 21 & 46 & 100 \\
\hline
\end{tabular}

${ }^{a}$ Calculated from the peak area in Figure 3(a).

${ }^{b}$ Alkyl chain length. 